\title{
Application Cases of Psychological Drama in Class Management
}

\author{
Liu Yanpeng \\ Hengshui High School, Hengshui, Hebei 053000, China
}

Keywords: psychodrama; class management; application

\begin{abstract}
The psychodrama plays a certain role in the self treatment of the students. This paper illustrates the application of the psychodrama in the class management by taking the practical case of the class management psychodrama as an example.
\end{abstract}

In 1921, Jacques Bouvier Moreno founded psychodrama in Vienna, Austria, he describes psychodrama as a method of exploring facts scientifically and effectively through comedy. He believes that humans are natural actors with a natural desire to act (The inner emotional state needs to be expressed to know the self and the world through personal experience; he believed that the innate innocence and intelligence of human beings are the motive force of spontaneous creativity, and psychological drama is the tool to awaken spontaneity). ${ }^{[1]}$ And because campus psychodrama is kind of student organization, it not only can solve the problems of student life, promote the growth of students in the process of rehearsal and performance, play a very good effect on promoting the relationship between teachers and students, improving student Art performance ability, but also can prevent and solve students' psychological problems in a better way. Meanwhile, it plays a very good role in class management. The author will expound the practice of applying campus psychological drama to class management.

When teaching grade ten in high school, the author took a class like this, a lot of children in the class have their own special skills, such as art specialty, music specialty, football specialty and dance specialty. The students have many talents, but they are always annoyed when learning. They have their own ideas and always feel that they have generation gap with teachers and parents, and the class cohesion is also poor.

As a head teacher in the class, I was struggling to figure out how to lead such a class, when the grade was organizing psychological plays, this opportunity came to me. I seized the opportunity and started my action, using campus psychological plays to promote class management.

\section{Finalize the subject, take the initiative}

At the beginning of the psychological drama soliciting performance in the grade, many classes, especially the teachers, were resistant to it. After all, it was very time-consuming, and I was also in the state of "watching" to see what was happening in the class. Later, one of my classmates, student A, took the initiative to prepare for the psychological drama. From the script writing to the recruitment of actors, it can be said that she was very attentive. This really gives me a headache, because I know that student A is a very active person in herself, and indeed has a lot of artistic talents. Like music and art, both of them are excellent in the class, and she also have a certain power of discourse among students. But she do not like study, although her parents and I have communicated many times, it has little effect. Open is better than close, I would like to use this opportunity to make a difference with her, her classmates and the whole class. I am ready to give it a try. So I took the initiative to find student A, and indicated that I would like to participate in the psychological drama performance. She is very happy to listen this, it can be great if head teacher attend, and with the joining of teachers, the rate at which psychodrama is screened through grade level may be higher. So I also joined in, and to discuss ideas with students, determine rehearsal time, training, doing all step by step. 


\section{Modify the script and incorporate ideas}

During the performance, we put forward some of our own ideas by combining with the ideas of the judges. Our play can highlight the features of music and should have the significance of education. After discussing with student A and other students, we finally determined our script. The main idea of the script is to focus on the conflicts between the dreams and the reality encountered by the protagonist student $\mathrm{A}$ in life, including home-school communication, teacher-student exchange, class collaboration, etc., showing a process in which student A has made progress. Of course, when designing the script, I moved my mind. The protagonist student $\mathrm{A}$ in the repertoire is actually the protagonist student A. They face the same problem of choice between dreams and learning. The class teacher $\mathrm{F}$ in the repertoire is actually my own. On the one hand, it is the pressure from the grades of the entrance examinations. On the one hand, I want to have a good educational effect on my children. I also need to take some measures. The parents in the repertoire are actually parents in reality. On the one hand, I hope that the children can achieve excellent results. On the one hand, I don't know how to communicate with children; the Rubberneck in the repertoire is actually the majority of children in real life, facing the same dream and realistic choice. In this way, we completed our script after the initial development of the idea, we also invited a special teacher to check our script. Because the script combines the ideas of teachers and classmates, through continuous modificationand finally achieved satisfactory results, laid a good foundation for the development of the entire psychological drama.

\section{The performance of the heart, the line is better than words}

The script is set, and the idea is fixed, but in fact, there are many difficulties in the performance process, such as the coordination of personnel, the arrangement of rehearsals, the pressure of exams in reality, the public opinion of parents, etc. These are not simple, in order to achieve good effect of the performance, we will refine the script repeatedly, rehearsing for each link, sometimes during the rehearsal we can not eat, we will order take-aways together. Sometimes I really feel that the process of preparation is more memorable than the process of performance. In this case, I feel that the distance between teachers and students is closer. The students also understand the difficulties of parents and teachers in the process of performance. I also understand the students' ideas. The students have some ideas and are more willing to communicate with me. We have really become "comrades-in-arms" who fight side by side. In the usual rehearsal, I have not forgotten the old head of the class teacher. The timely classmates completed the homework of each subjectand also uploaded the wonderful moments and timely photos of the rehearsal to the parents in time. Our heart is approaching a little. On the day of the performance, I also specially invited the parents of all the students who participated in the performanceand issued an invitation among the parents, many parents went to the scene to watch the performance. Many parents said that the students performed very well, especially the parents of the children who performed on stageand were more happy with the performance of the children. The most happy thing is me, not only because I participated in the performance, but more importantly, my educational thoughts have been shown on the spot, and it has also improved the cohesiveness of the class.

\section{The end of the show, class condensate}

Of course, to return to the theme, our initial purpose is not only to perform such a repertoire, but more importantly, what can such a psychological drama bring us? The small partners and parents who came to the stage were educated, and the classmates and parents who watched it also had deep feelings. The most important thing is to see the changes in the class and the class within the class after the show. Take student A as an example, after this performance, like the Student A in the psychological drama and began to study hard and fight for his own dream. Other actors in the psychological drama also returned to the "ordinary" because they had gotten the "halo". In the life to pursue their dreams; the parents of psychological actors are also more adept at communicating 
with the teachers and classmates, to better guiding the children; of course, those children who are not participated in, through psychological drama got an education, and each classmate was proud of the fact that the class was able to direct such a psychological drama. All the students fulfilled their commitments in the psychological drama, studied harder and worked harder to improve their own strengths. After that performance, I held a parent meeting and at the parents meeting, we re-showed our psychological drama performance to all parents and gave awards to all the students who participated in the performance. The participating students got the opportunity to show and be praised, all the teachers and students present at the scene were once again educated and encouraged. Later, the class also took this opportunity to slowly step into the right track, and constantly made progress and honors. I am also proud of having such an excellent class.

There is a foreign saying: "You realise what you heard, you know what you saw, and only you really understand it after you do it!" Thanks to this psychological drama, I have the opportunity to practice. According to the relevant provisions of the "Implementation Opinions of the State Council on Deepening the Reform of the Enrollment System" and the "Opinions of the Ministry of Education of the Ministry of Public Security of the Ministry of Public Security of the State Administration of Science and Technology of the State Council of Science and Technology on Further Reducing and Regulating the Entrance Examination Points and Points of the College Entrance Examination" National special college entrance examinations, such as sports specialties, middle school students' Olympic competitions, science and technology competitions, provincial outstanding students, and ideological and political morals. Only the art speciality has not been canceled by the Ministry of Education for the college entrance examination! The documents of the Ministry of Education have made the following provisions for the evaluation of students' comprehensive quality: comprehensive quality evaluation includes five items: ideological and moral, academic level, physical and mental health, artistic literacy and social practice. The focus of artistic literacy is on music, art, dance and drama. Interests in the areas of drama, film, and calligraphy, and the achievements of art activities. The state still pays attention to art education, and psychological drama is a good form of artistic experience. So far, psychological drama treatment has developed and promoted in the past 90 years. Through the efforts and promotion of psychologists around the world, psychological drama has become an important psychotherapy genre when Jacob Moreno died in 1974. ${ }^{[2]}$ I think that the psychological drama not only gives us an opportunity for an artistic experience, but also gives us a different class. It also enhances the educational wisdom as a teacher and hopes that the future education path will be better and better.

\section{References}

[1] Li Danping. Research on self-identity intervention of middle school students in psychological drama [D]. Southwest University, 2012.

[2] Fu Cong. Exploring the Shaman Treatment Gene in Musical Psychology_-Taking the Horqin Mongolian Shaman Treatment Ceremony as an Example[D]. China Conservatory of Music, 2015. 